\title{
A systematic review of children's construction of the self: implications for children's subjective well-being
}

\author{
Elizabeth Benninger and Shazly Savahl
}

\begin{abstract}
This research aimed to systematically review academic literature focused on how children construct and assign meaning to the 'self.' An article search and appraisal yielded 38 articles that met the inclusion criteria. Within these articles, six central thematic categories emerged as the key influences on children's constructions of the self. These include multidimensionality, discursive practices, socio-environmental conditions, oppression \& marginalisation, culture, and social support. The study highlights the multidimensional and fluid nature of the self and emphasises the self-concept to be mutually influenced and supported by an individual's immediate social networks, socio-environmental resources, and internal processes. A child's ability to meaningfully construct a sense of self was associated with higher levels of coping and resilience and improved well-being. The review provides considerations for increased interventions aimed at improving child well-being which must take into account the unique ways in which children construct and assign meaning to the self. Such interventions should be inclusive of the individual and contextual issues influencing a child's self-constructions, including coping skills, structural challenges and proximal economic and social resources.
\end{abstract}

\section{Introduction}

The way in which children construct and assign meaning to the 'self' plays a crucial role in a child's healthy development, behaviour, as well as their overall well-being. Furthermore, a child's understanding of the 'self' could influence the way in which they make meaning out of their experiences and internalize these experiences as a means of understanding one's abilities and self-worth. In Social Psychology the conscious component of the 'self' is commonly referred to as the self-concept or self-identity. The self-concept is defined to be construct created as a reflection of a child's interaction with their social environment and the way children think about themselves in relation to their abilities and attributes (Kenny and McEachern 2009). While a positive self-concept has been linked to academic, school, and positive psychosocial development, a negative view of the self has been linked to aggression, depression, eating disorders, adjustment problems, suicide, and shame (Demaray et al. 2009; Margolin and Gordis 2000; McLean et al. 2010; Neff et al. 2007). Furthermore, research has shown a stable self to be a key component of children's subjective well-being (Savahl et al. 2015). Multiple fields in psychology and sociology recognise the valuable 
influence of self-concept in optimal social, psychological, and developmental outcomes. Humanistic psychology, for example, makes reference to the crucial development of a healthy self-concept as positive self-regard and unconditional self-acceptance. The behavioural-based model of the self-concept theorises an individual's self-concept to be reflected in their unique patterns of behaviour. People experience a healthy self-concept through the development of successes in the various life domains accompanied by positive feedback from the environment (Bracken and Lamprecht 2003). According to Mead (1934):

The self is something which has a development; it is not initially there, at birth, but arises in the process of social experience and activity, that is, develops in the given individual as a result of his relations to that process as a whole and to other individuals within that process (p. 135).

Social psychology's "looking glass self-theory," (Cooley 1902) postulates self-conceptions to be shaped by the way people are viewed and acted on by the environment in response to their behaviours. The 'sociocultural self-model' builds on this theory to describe the transactional relationship between individuals and their environment. Individuals and structures influence one another in an on-going cycle whereby individuals shape their different selves in response to their social and cultural experience (Stevens et al., 2012). While the self is shaped by cultural experiences, new sub-cultures can simultaneously arise in the form of the interactions of the individual selves within them (Adams and Markus 2004). As new patterns emerge, cultural norms, meanings, and identities influence and support the new patterns.

The conditions within an individual's environment influence the experiences which they draw upon to construct the self. For example, violence exposure within a child's environment could be internalised by a child in the form of negative self-perceptions and feelings, such as an unworthiness of being kept safe (Margolin and Gordis 2000). Research has suggested that high exposure to violence influences children's self-constructions and perpetuates violence through aggressive cognitions and behaviour (Guerra et al. 2003; Schwartz and Gorman 2003). Research further indicates increased risk for internalised psychological symptoms in children who have been victimised or exposed to community violence, such as helplessness, shame, fear, anger, high arousal, anxiety, and depression (see Margolin and Gordis 2000; Staub 2003). These reactions could interfere with a child's social and academic life, and alter a child's developmental trajectory and construction of a healthy self-concept (Margolin and Gordis 2000). Socio-economic status could also influence the resources available for a child's self-construction. For example, impoverished communities with poor infrastructure may have limited spaces for children to safely explore their surroundings and to form supportive relationships with others, all of which could influence the self-concept.

In order to see large-scale changes in child well-being, communities need to be exposed to promotional activities focused on improving overall quality of life. Research has identified the key factors of social support, coping skills, and self-concept as having a strong influence on child well-being (see Cluver and Gardner 2007; Fattore et al. 2007; September and Savahl 2009). Due to the complex and contextual nature of the 'self', self- 
concept enhancing interventions remain scarce. The concept of the 'self' cannot be easily defined and must be located within an individual's complex web of history, culture, community, character, and space. Although there is a large body of research measuring self-concept, the majority of these studies look to the quantitative aspects and self-perceptions through the use of scales such as the Harter's Perceived Competence Scale for Children (Harter 1982), the Piers-Harris SCS (Piers 1969) and the Rosenberg Self-esteem scale (Rosenberg 1965). According to Blascovich and Tomaka (1991), there are over 200 measures of self-esteem, although the validity of the scales remains questionable. Furthermore, the majority of these scales have been developed within a United States context. Additionally, there are limited studies on how messages of oppression, violence, and poverty impact on the subjective understanding of self-concept with children. Further research is therefore required to provide deeper insight into children's understanding and meaning assignation of the 'self,' across child populations and contexts. The overarching aim of this article was to provide a systematic review of existing empirical studies focused on understanding the ways in which children construct and assign meaning to the 'self'. In the absence of systematic reviews, this study hopes to fill this gap in international discourse on children's self-concept.

\section{Method}

The review was conducted by the primary author, trained in clinical and research psychology, as a part of a PhD dissertation. The second reviewer and co-author is a research psychologist who specialises in child and youth research. The systematic review is at the core of evidence-based practice in the medical, health, and social sectors. Its usefulness goes beyond theory to promote the development of practices, interventions, and services based on the best available knowledge. A systematic review draws upon the validity and usefulness of existing research findings to assist with the further development of evidence-based practices, interventions, and theories (Long and Godfrey 2004) Additionally, the systematic review method is an efficient way to become familiar with the best available research evidence for a focused research question (Garg et al. 2008). The strength of a systematic review is in the transparency of each phase of the synthesis process, which provides a detailed and critical understanding of existing studies (Garg et al. 2008). This process also identifies the applicability and gaps in current research across populations and contexts.

Since the specific research question is concerned with the subjective experiences and meaningmaking processes, the review largely, although not exclusively, focuses on qualitative research studies, since these are the studies most relevant to the research question under investigation. Pearson (2004) highlights the importance of incorporating qualitative research into the systematic review in order to broaden the view of what constitutes best practice. Incorporating qualitative research takes into consideration different research questions where quantitative studies may be less applicable, providing a different kind of evidence and insight into a problem or area of interest, drawing out subjective perceptions and understandings while incorporating the specific context and culture (Long and Godfrey 2004) 


\section{Review Question How do children construct and assign meaning to the 'self'?}

Included Databases EbscoHost, ScienceDirect, and SpringerLink are the metadatabases which were searched for the extraction of articles. Databases within EbscoHost included PsychARTICLES, SocINDEX, and Academic Search Complete. Within ScienceDirect and SpringerLink, the search was conducted in the fields of psychology and social sciences. Articles with titles and abstracts which met the inclusion criteria were obtained and reference lists of the identified articles scanned to identify additional relevant articles. Personal contact was also made with experts in the field on the topic of self-concept who may be able to direct the researcher to relevant studies.

Time Period/Inclusion/ Exclusion Criteria (1) The time period considered is the last 20 years (1994-2014). (2) Participants are children age 18 or under (3) Study seeks to make meaning of how children conceptualise the self (4) Study provides a full report written in English. (5) Study is published in an English-language, peer-reviewed journal, book or book chapter. Articles which did not meet criteria were excluded.

Key Words The preliminary keywords used within the search were child, self, self-concept, self-esteem, self-competence, self-efficacy, self-perceptions, child narratives, meaning-making, qualitative analysis, perceptions of the self. The list entailed the terms which have been commonly utilised in studies related to child self-concept. During the initial search, the majority of the studies were related to the objective measures of the self-concept, rather than the meaning-making processes and subjective experiences of children. It was therefore decided not to include the term perception in the search. It was also decided to use the exclusion terms self-evaluation, scale, man, woman and adult within the search. Self-identity was a term which was found in many articles interchangeably with self-concept. Additionally, the term narrative was included because this term is commonly utilised in studies which seek to understand children's meaning-making processes related to a concept. It was then decided to complete the final search utilising the keywords: child OR children's constructions OR children's narratives OR children's meaning AND OR self AND OR self-concept AND OR identity.

Quality Assessment Quality assessment of the studies that met the inclusion criteria were rated using the Crowe Critical Appraisal Tool (CCAT). The purpose of a quality assessment within a systematic review is to determine the quality of the research studies through critical assessment of the research strengths, weaknesses, and benefits. The CCAT has been selected for the purpose of this systematic review due to the tool's depth to fully assess research papers, appropriate scoring system, and validity and reliability (Crowe, 2011). Furthermore, the CCAT can be applied to qualitative, quantitative, and mixed methods research, and can be used to assess, understand and communicate research knowledge (see Donnelly et al. 2015; Mellon et al. 2015). A threshold score of $70 \%$ was used as the inclusion criteria.

Data Extraction The researcher extracted the data which was checked by a second reviewer. The data was extracted following the procedures of meta-synthesis and 
formatted into a table commonly utilised for data extraction. The table was formatted to extract data specifically relevant to the research question, which included the study authors, aim, sample size, participant characteristics, research design, outcomes, themes, and self-concept domain.

Analysis The data from the studies were analysed using metasynthesis, which is a form of data analysis commonly utilised within systematic reviews that include both quantitative and qualitative studies (see Bennion et al. 2012; Dolman et al. 2013; Wells et al. 2013). The analysis followed a process of reading, rereading, and taking notes of the key aims, methods, and findings of each article (Bennion et al. 2012). This was followed by data extraction, which is characterised by a recording and the thematic coding of the findings of the articles. Thematic coding commenced through the consideration of the data extraction table along with a review of the notes. The findings were coded into themes and sub-themes, by means of a cyclical process, whereby studies were checked and rechecked for new emerging themes (Bennion et al. 2012). Contradictory and complimentary links between texts were used to bring about new understandings and perspectives (Dixon-Woods et al. 2005). The final themes and key findings are presented in the results section.

\section{Results}

Article Search Procedure The articles were initially obtained through a search procedure of the selected databases. The key words children's constructions or children's narratives or children's meaning and or self and or self-concept and or identity were searched within the selected databases and yielded a total of 1762 hits. A title search followed by an abstract search narrowed down the studies to 314 which met the criteria. The articles were then reviewed and appraised through the use of the CCAT. A total of 20 articles met the criteria. The references of the articles which met the criteria were then search for further relevant articles. An additional 18 articles which met the criteria were found through the reference mining. (see Tables 1 and 2).

Table 1 Article search procedure
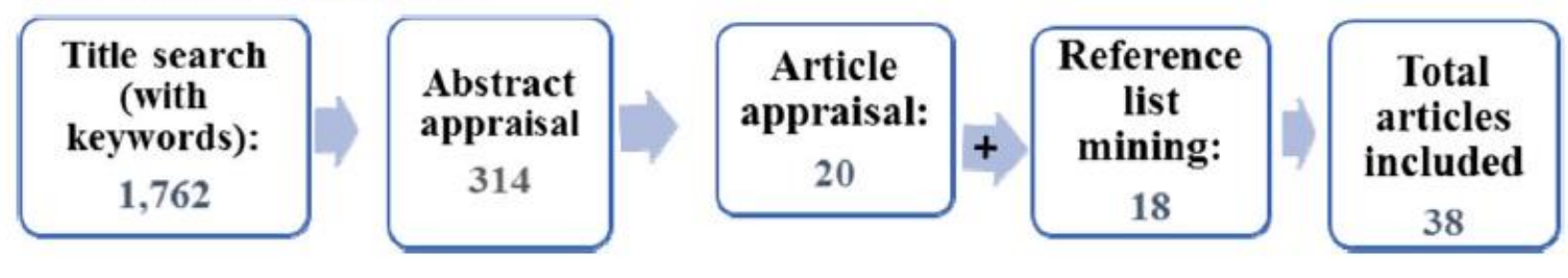

\section{Design of Reviewed Studies}

The design of the reviewed studies can be categorised as qualitative, descriptive/ observational/ exploratory, and mixed methods. Within these categories there were eight subcategories which included; narrative, ethnography, grounded theory, concurrent mixed methods, correlational, longitudinal, prospective, and case-control. The categories were line up with those described in the CCAT, which was utilised to assess the quality of the studies. 
Narrative and ethnographic studies were the most common design utilised, with a total of 13 studies. Ten of the studies utilised a grounded theory design, four mixed methods, three correlational, one longitudinal, one prospective, and one case-control study. Seventeen utilised more than one research design.

The data collection tools within the studies included in-depth, informal, and semi-structured interviews, focus group discussions, participant observations, field notes, self-report questionnaires, and creative arts such as drawings, photos, and puppet shows. Data analysis procedures included thematic content analysis, narrative analysis, correlational analysis, statistical analysis, descriptive analysis, inductive analysis, narrative case study, grounded theory comparative analysis, discourse analysis, qualitative content analysis, qualitative comparative analysis, phenomenological analysis, and constant comparative analysis (See Table 3).

\section{Self-Concept Domain}

Fourteen thematic domains of the self were included within the studies. These domains included the global, narrative, situational, collective, cultural and ethnic, racial, gender, athletic and academic selves, self-identity, self-efficacy, self-worth, self-regard, and self-esteem (See Table 4).

Table 2 Article search procedure

\begin{tabular}{|c|c|c|c|c|c|}
\hline $\begin{array}{l}\text { Metadatabases } \\
\text { searched }\end{array}$ & Keys words/Phrases & Hits & $\begin{array}{l}\text { Meets } \\
\text { criteria }\end{array}$ & $\begin{array}{l}\text { Reference } \\
\text { mining }\end{array}$ & $\begin{array}{l}\text { Total } \\
\text { meetscriteria }\end{array}$ \\
\hline Ebscohost & $\begin{array}{l}\text { Child OR children's } \\
\text { constructions } \\
\text { OR children's narratives } \\
\text { OR children's meaning AND } \\
\text { OR self AND OR self-concept } \\
\text { AND OR identity. }\end{array}$ & 813 & 10 & 12 & 22 \\
\hline Springerlink & & 703 & 9 (6 new) & 6 & 12 \\
\hline \multirow[t]{2}{*}{ Sciencedirect } & & 153 & 4 & 0 & 4 \\
\hline & & & & Total & 38 \\
\hline
\end{tabular}


Table 3 Study design

\begin{tabular}{|c|c|c|}
\hline Study design & Number & Author (s) *Multiple methods \\
\hline Qualitative: Narrative & 13 & $\begin{array}{l}\text { Ahn and Filipenko (2007), Mclean et al.(2010), Wang (2004), } \\
\text { Bohanek et al. (2006), *McLean and Breen (2009), * } \\
\text { Welch-Ross et al. (1999), Cockle (1994), Anagnostopoulos } \\
\text { et al. (2006), Graham and Anderson (2008), *Hung et al. } \\
\text { (2011), McLean and Jennings (2012), *Roth (2004), } \\
\text { *McMurray et al. (2011) }\end{array}$ \\
\hline Qualitative: Ethnography & 13 & $\begin{array}{l}\text { Hammack (2010), Isom (2011), Kickett-Tucker (2009), } \\
\text { *Fernández-Kelly and Schauffler (1994), Moses (2006), } \\
\text { *Timberlake (1994), *De Haan et al. (2010), *Hung et al. } \\
\text { (2011), Lim (2008), Gernhardt et al. (2014), Valentine (2000), } \\
\text { *Campos Monteiro and Dollinger (1998), Abrams and Aguilar } \\
\text { (2005) }\end{array}$ \\
\hline Qualitative: Grounded Theory & 10 & $\begin{array}{l}\text { Rogers et al. (2012), Noble-Carr et al. (2013), McMurray et al. } \\
\text { (2011), *Campos Monteiro and Dollinger(1998), Moss (2009), } \\
\text { *Timberlake (1994), Johnson (2014), Purdie et al.(2000), } \\
\text { *Roth (2006), *McMurray et al. (2011) }\end{array}$ \\
\hline Mixed methods (concurrent) & 4 & $\begin{array}{l}\text { Fernández-Kelly and Schauffler (1994), *De Haan et al. (2010), } \\
\text { McLean and Jennings (2012), *Campos Monteiro and } \\
\text { Dollinger (1998), Bohanek et al. (2008) }\end{array}$ \\
\hline $\begin{array}{l}\text { Descriptive/ observational/ } \\
\text { exploratory: Correlational }\end{array}$ & 3 & $\begin{array}{l}\text { Kiang and Fuligni (2010), Egan and Perry (1998), } \\
\text { *McLean and Breen (2009) }\end{array}$ \\
\hline $\begin{array}{l}\text { Descriptive/ observational/ } \\
\text { exploratory: Longitudinal }\end{array}$ & 1 & Whitesell et al. (2006) \\
\hline $\begin{array}{l}\text { Descriptive/ observational/ } \\
\text { exploratory: Prospective }\end{array}$ & 1 & *Welch-Ross et al. (1999) \\
\hline $\begin{array}{l}\text { Descriptive/ observational/ ex- } \\
\text { ploratory: Case-control }\end{array}$ & 1 & Macfie and Swan (2009) \\
\hline
\end{tabular}

\section{Demographics}

The participants of the studies were identified to be from 19 different racial or ethnic categories. These included European American, African American, Asian American, Native American, Dominican American, Russian American, British (Caucasian), Dutch, Palestinian, Singaporean, Greek, Brazilian, Caucasian Australian, Indigenous Australian, German, Turkish, South African (mixed race) and New Zealander. Twenty-one of the studies were conducted amongst Americans, with the majority of the studies amongst dominantly European American participants $(\mathrm{n}=9)$ (see Table 5).

Age The largest proportion of the studies were amongst adolescent participants $(n=22)$, followed by middle childhood participants $(n=17)$, with the least amount amongst participants in early childhood $(n=7)$ (See Table 6). 
Table 4 Self-concept domain

\begin{tabular}{|c|c|c|}
\hline $\begin{array}{l}\text { Self-concept } \\
\text { domain }\end{array}$ & Number & Author (s) \\
\hline $\begin{array}{l}\text { Cultural/ ethnic } \\
\text { self }\end{array}$ & 8 & $\begin{array}{l}\text { Wang (2004),Campos Monteiro and Dollinger (1998), Whitesell et al. (2006), } \\
\text { Anagnostopoulos et al. (2006), Graham and Anderson (2008), De Haan et al. } \\
\text { (2010), Gernhardt et al. (2014), Roth (2006) }\end{array}$ \\
\hline Self esteem & 7 & $\begin{array}{l}\text { Kiang and Fuligni (2010), Moss (2009), Bohanek et al. (2008), McLean et al. } \\
\text { (2010), Reese et al. (2007), Purdie et al. (2000), Valentine (2000) }\end{array}$ \\
\hline Self-identity & 5 & $\begin{array}{l}\text { Whitesell et al. (2006), Rogers et al. (2012), Noble-Carr et al. (2013), Hammack } \\
\text { (2010), McMurray et al. (2011) }\end{array}$ \\
\hline Self-efficacy & 5 & $\begin{array}{l}\text { Egan and Perry (1998), Bohanek et al. (2006), Moses (2006), Clinkinbeard and } \\
\text { Murray (2012), Abrams and Aguilar (2005) }\end{array}$ \\
\hline Global Self & 4 & McLean et al. (2010), Cockle (1994) \\
\hline Self-Worth & 4 & $\begin{array}{l}\text { Reese et al. (2010), Timberlake (1994), Macfie and Swan (2009), Reese et al. } \\
\text { (2007) }\end{array}$ \\
\hline Self-regard & 1 & Egan and Perry (1998) \\
\hline Collective self & 4 & $\begin{array}{l}\text { Whitesell et al. (2006), Campos Monteiro and Dollinger (1998), Fernández-Kelly } \\
\text { and Schauffler (1994), Valentine (2000) }\end{array}$ \\
\hline Racial self & 3 & Isom (2007), Kickett-Tucker (2009), Johnson (2014) \\
\hline Academic Self & 3 & Graham and Anderson (2008), Lim (2008), Roth (2006) \\
\hline Narrative self & 4 & $\begin{array}{l}\text { Ahn and Filipenko (2007), McLean and Breen (2009), Reese et al. (2010), Welch- } \\
\text { Ross et al. (1999) }\end{array}$ \\
\hline Gender self & 2 & Isom (2007), Johnson (2014) \\
\hline Situational self & 2 & McMurray et al. (2011), Timberlake (1994) \\
\hline Athletic self & 1 & Hung et al. (2011) \\
\hline
\end{tabular}

Socio-Economic Status The greatest number of studies took place amongst participants from a low socioeconomic status background $(n=14)$, closely followed by participants from medium socioeconomic status background $(n=12)$, and lastly participants from a high socioeconomic background ( $\mathrm{n}=1$ ) (see Table 7 ).

Region The regions where the studies took place include 13 different countries; USA, Canada, UK, Holland, Palestine, Singapore, Greece, Brazil, Australia, Germany, South Africa, China, and New Zealand. Although this represents a diversity of global regions, there remains a limited amount of studies within developing countries with the vast majority of the studies $(\mathrm{n}=23)$ within the United States (see Table 8).

Research Context The research context of the studies was categorised into school, home, community/ neighbourhood, social service, after-school programme and university laboratories. The most common space used was the schools $(n=17)$ followed by the 
home $(n=9)$ and the community/ neighbourhood $(n=7)$. The least common space was the university laboratories and an after-school programme setting $(n=2)$ (See Table 9).

Table 5 Demographics

\begin{tabular}{|c|c|c|}
\hline Race & Number & Author $*$ Multiple racial/ethnic groups \\
\hline European American & 9 & $\begin{array}{l}\text { Ahn and Filipenko (2007), Bohanek et al. (2006), } \\
\text { Bohanek et al. (2008), Egan and Perry (1998), } \\
\text { Mcleen et al. (2011), McLean and Jennings (2012), } \\
\text { McLean and Breen (2009), Valentine (2000), } \\
\text { Welch-Ross et al. (1999) }\end{array}$ \\
\hline $\begin{array}{l}\text { USA multiple ethnicities (i.e. Dominican, } \\
\text { Chinese, Russian, African, European, } \\
\text { Hmong) }\end{array}$ & 8 & $\begin{array}{l}\text { Abrams and Aguilar (2005), Clinkinbeard and } \\
\text { Murray (2012), Fernández-Kelly and Schauffler } \\
\text { (1994), Kiang and Fuligni (2010), Lim (2008), } \\
\text { Rogers et al. (2012), Timberlake (1994), Wang } \\
\text { (2004) }\end{array}$ \\
\hline Australian (white and indigenous) & 4 & $\begin{array}{l}\text { Kickett-Tucker (2009), Moss (2009), Noble-Carr et } \\
\text { al. (2013), Purdie et al. (2000), }\end{array}$ \\
\hline African American & 3 & $\begin{array}{l}\text { Graham and Anderson (2008), Isom (2007), Roth } \\
\text { (2006) }\end{array}$ \\
\hline New Zealander & 2 & Reese et al. (2007), 2010 \\
\hline British (White) & 1 & McMurray et al. (2011) \\
\hline Asian American & 1 & Cockle (1994) \\
\hline Dutch (multiple ethnicities) & 1 & De Haan et al. (2010) \\
\hline Palestinian & 1 & Hammack (2010) \\
\hline Singaporean & 1 & Hung et al. (2011) \\
\hline Greek (Minority) & 1 & Anagnostopoulos et al. (2006) \\
\hline Brazilian & 1 & Campos Monteiro and Dollinger (1998) \\
\hline Native American & 1 & Whitesell et al. (2006) \\
\hline German & 1 & *Gernhardt et al. (2014) \\
\hline Turkish & 1 & *Gernhardt et al. (2014) \\
\hline South African (mixed race) & 1 & Moses (2006) \\
\hline Unspecified & 1 & Macfie and Swan (2009) \\
\hline
\end{tabular}

\section{Emerging Themes}

Six central thematic categories emerged as the key influences on the way in which children construct and assign meaning to the 'self.' These included; multidimensionality, discursive practices, environmental conditions, oppression and marginalisation, culture, and social support. 
Multidimensionality The first common theme which emerged from the studies was the multidimensional nature of the self which was situation specific and fluid. The studies combined showed the variety of influences on a child's self-development, including culture, environmental and structural conditions, developmental processes and social interactions. Within the research, the self was made up of multiple domains, including global, academic, racial, ethnic, gender, athletic, and collective self. Although the studies were divided into multiple self-concept domains, these domains often overlapped with other domains, largely dependent on the specific sociocultural situation.

Table 6 Age

\begin{tabular}{|c|c|c|}
\hline AGE & Number & Author (s) * Multiple age groups \\
\hline $\begin{array}{l}\text { Adolescence } \\
\qquad(12-18)\end{array}$ & 22 & $\begin{array}{l}\text { Abrams and Aguilar (2005), Anagnostopoulos et al. (2006), *Campos } \\
\text { Monteiro and Dollinger (1998), Clinkinbeard and Murray (2012), } \\
\text { Fernández-Kelly and Schauffler (1994), Graham and Anderson (2008), } \\
\text { Hammack (2010), Johnson (2014), *Kickett-Tucker (2009), Kiang and } \\
\text { Fuligni (2010), Lim (2008), *Moses (2006), *McMurray et al. (2011)* } \\
\text { Mcleen et al. (2011), McLean and Jennings (2012), McLean and Breen } \\
\text { (2009), *Noble-Carr et al. (2013), Purdie et al. (2000), Reese et al. (2010), } \\
\text { Roth (2006), *Valentine (2000), Whitesell et al. (2006), }\end{array}$ \\
\hline $\begin{array}{l}\text { Middle childhood } \\
\quad(5-12)\end{array}$ & 17 & $\begin{array}{l}\text { Bohanek et al. (2006), Bohanek et al. (2008), Cockle (1994), *Campos } \\
\text { Monteiro and Dollinger (1998), De Haan et al. (2010), Egan and Perry } \\
\text { (1998), Hung et al. (2011), Isom (2007), *Kickett-Tucker (2009), * Macfie } \\
\text { and Swan (2009), *Moses (2006), *Purdie et al. (2000), Rogers et al. (2012), } \\
\text { Reese et al. (2010), *Reese et al. (2007), Timberlake (1994), *Valentine } \\
\text { (2000), }\end{array}$ \\
\hline $\begin{array}{l}\text { Early Childhood } \\
\quad(0-5)\end{array}$ & 7 & $\begin{array}{l}\text { Ahn and Filipenko (2007), Gemhardt et al. (2014), Purdie et al. (2000), Macfie } \\
\text { and Swan (2009), Moss (2009), Welch-Ross et al. (1999), Wang (2004) }\end{array}$ \\
\hline
\end{tabular}

For example, Purdie et al. (2000) focused on the positive self-identity for Indigenous students and its relationship to school. The participants in the study were faced with conflicting messages about education from their traditional community versus their mainstream school environment. A positive self-identity as an Indigenous young person was not necessarily linked with successful academic outcomes, however successful academic outcomes were linked to a positive self-identity as a student. Self-concept additionally became situation specific for many participants as they experienced feelings of pride when relating to others in their community and experiences of shame while attending a mainstream schooling environment where there existed negative messages around the indigenous culture. A further example of the multidimensional nature of the self was seen within the study by McMurray et al. (2011). 
Table 7 Socio-economic status

\begin{tabular}{|c|c|c|}
\hline SES & Number & Author (s) \\
\hline Low & 14 & $\begin{array}{l}\text { Abrams and Aguilar (2005), Anagnostopoulos et al. (2006), Campos Monteiro and } \\
\text { Dollinger (1998), Fernández-Kelly and Schauffler (1994), Graham and Anderson } \\
\text { (2008), Isom (2007), Johnson (2014), McMurray et al. (2011), Roth (2006), Moses } \\
\text { (2006), Kickett-Tucker (2009), Timberlake (1994), Whitesell et al. (2006), Moss } \\
\text { (2008) }\end{array}$ \\
\hline Medium & 12 & $\begin{array}{l}\text { Bohanek et al. (2006), Bohanek et al. (2008), Egan and Perry (1998), Hung et al. } \\
\text { (2011), McLean and Jennings (2012), McLean and Breen (2009), McLean et al. } \\
\text { (2010), Reese et al. (2010), Valentine (2000), Wang (2004), Welch-Ross et al. } \\
\text { (1999), Reese et al. (2007), }\end{array}$ \\
\hline High & 1 & Ahn and Filipenko (2007) \\
\hline Mixed SES & 9 & $\begin{array}{l}\text { Clinkinbeard and Murray (2012), De Haan et al. (2010), Gernhardt et al. (2014), } \\
\text { Hammack (2010), Kiang and Fuligni (2010), Lim (2008), Noble-Carr et al. (2013), } \\
\text { Rogers et al. (2012), Purdie (2000) }\end{array}$ \\
\hline Unspecified & 2 & Cockle (1994), Macfie and Swan (2009) \\
\hline
\end{tabular}

Table 8 Region

\begin{tabular}{|c|c|c|}
\hline Region & Number & Author $*$ Multiple regions \\
\hline USA & 23 & $\begin{array}{l}\text { Ahn and Filipenko (2007), Cockle (1994), Clinkinbeard and Murray (2012), Egan and } \\
\text { Perry (1998), Bohanek et al. (2006), Bohanek et al. (2008), Reese et al. (2007), } \\
\text { Reese et al. (2010), Valentine (2010), Welch-Ross et al. (1999), McLean and } \\
\text { Jennings (2012), Isom (2006), Graham and Anderson (2008), Roth (2007), } \\
\text { Whitesell et al. (2006), Kiang and Fuligni (2010), Rogers et al. (2012), Fernández- } \\
\text { Kelly and Schauffler (1994), Lim (2008), Abrams and Aguilar (2005), Timberlake } \\
\text { (1994), Macfie and Swan (2009) *Wang (2010) }\end{array}$ \\
\hline Australia & 4 & Moss (2009), Purdie et al. (2000), Noble-Carr et al. (2013), Kickett-Tucker (2009) \\
\hline Canada & 2 & McLean and Jennings (2012), McLean and Breen (2009) \\
\hline UK & 2 & McMurray et al. (2011), Valentine (2000) \\
\hline $\begin{array}{l}\text { New } \\
\quad \text { Zealand }\end{array}$ & 2 & Reese et al.(2007), Reese et al. (2010) \\
\hline $\begin{array}{l}\text { South } \\
\text { Africa }\end{array}$ & 1 & Moses (2006) \\
\hline Singapore & 1 & Hung et al. (2011) \\
\hline Greece & 1 & Anagnostopoulos et al. (2006) \\
\hline Brazil & 1 & Campos Monteiro and Dollinger (1998) \\
\hline Palestine & 1 & Hammack (2010) \\
\hline Germany & 1 & Gemhardt et al. (2014) \\
\hline China & 1 & *Wang (2004) \\
\hline Holland & 1 & De Haan et al. (2010) \\
\hline
\end{tabular}


The study presented an analysis of semi-structured interviews with 13 young people who were in residential and non-residential care and their social workers. The young people in the sample exhibited different identities in different contexts which were largely shaped by their relationships, often rooted in family, role models, and current experiences. The study presented positive social relationships to be of key importance for the development of a secure sense of self. While the study provided a valuable insight into the self-concept of young people in care, the participants consisted of only Caucasian young people who were either born or had lived locally for many years and therefore did not necessarily struggle with issues related to their ethnic or cultural identities. The authors recommended further research explore the self-concept of children in care from other sociocultural backgrounds.

Also amongst children in care, Moss (2009) explored identity issues for indigenous children in foster care, specifically focused on the domains of self-esteem and sense of self as it was interconnected with their cultural identity. The findings demonstrated key differences in cultural connectedness, self-esteem, identity, and psychological well-being for indigenous children in out of home care compared to those not in care. Young people in care were much more likely to have self-esteem issues and displayed a poor sense of self in comparison to children not in care. Similar to the findings of McMurray et al. (2010), family and other significant social relationships, such as social workers and peers, all contributed towards the participants' self-concept. A connection with one's cultural background was additionally identified to be an important factor for a stable self-concept. 


\begin{tabular}{|c|c|c|}
\hline Context & Number & Author $*$ Multiple contexts \\
\hline School & 17 & $\begin{array}{l}\text { Ahn and Filipenko (2007), Cockle (1994), De Haan et al. (2010), *Fernández- } \\
\text { Kelly and Schauffler (1994), Gemhardt et al. (2014), * } \\
\text { Graham and Anderson (2008), Kiang and Fuligni (2010), Lim (2008), } \\
\text { McLean et al. (2010), McLean and Breen (2009), Kickett-Tucker (2009), } \\
\text { *Purdie et al. (2000), Rogers et al. (2012), Roth (2006), *Timberlake (1994), } \\
\text { Valentine (2000), Wang (2004) }\end{array}$ \\
\hline Home & 9 & $\begin{array}{l}\text { Bohanek et al. (2006), Bohanek et al. (2008), *Fernández-Kelly and Schauffler } \\
\text { (1994), * Graham and Anderson (2008), Johnson (2014) Macfie and Swan } \\
\text { (2009), McLean and Jennings (2012), } \\
\text { *Purdie et al. (2000), Welch-Ross et al. (1999) }\end{array}$ \\
\hline $\begin{array}{l}\text { Community/ } \\
\text { Neighbourhood }\end{array}$ & 7 & $\begin{array}{l}\text { Campos Monteiro and Dollinger (1998), *Graham and Anderson (2008), } \\
\text { Hammack (2010), Moses (2006), * Purdie et al. (2000), } \\
\text { *Timberlake (1994) Whitesell et al. (2006) }\end{array}$ \\
\hline Social Service & 6 & $\begin{array}{l}\text { Abrams and Aguilar (2005), Anagnostopoulos et al. (2006), Clinkinbeard and } \\
\text { Murray (2012), McMurray et al. (2011), Moss (2009), Noble-Carr et al. } \\
\text { (2013), }\end{array}$ \\
\hline $\begin{array}{l}\text { After-School } \\
\text { Programme }\end{array}$ & 2 & Hung et al. (2011), Isom (2007) \\
\hline $\begin{array}{l}\text { University } \\
\text { Laboratory }\end{array}$ & 2 & Reese et al. (2007), 2010 \\
\hline
\end{tabular}

The study by Hung et al. (2011) explored the connection of self and community, specifically in the form of the projective identity of an 11-year-old and how this interplayed with his athletic self-concept as a bowler. The projective identity framework views the self to be developed as individual observe the actions of role models, compare them, and marks certain patterns of action relative to their own, then refines their own actions. The study illuminated how the participant developed an identity as a bowler over time through his narrative, dialogue, and performative actions. The participant actualized his bowler identity through the three projective identity stages of identity tinkering, identity negotiating, and identity sustaining. The single case-study method provided a valuable example of the utilisation of the projective identity framework for understanding children's self constructions, specifically related to the bowler identity. However, further research could improve the understanding of the self through the application of the projective identity framework within other sporting or extra-mural environments and sociocultural contexts.

Isom (2007) aimed to illuminate the meaning making world of children and their constructions of racial and gender identities amongst a sample of 75 African American children aged 10 to 12. Identity in this context emerged as diverse and shifting, while reflecting a strong desire for a self apart from external constructions. Hammack (2010) explored the complexity of the relationship between the personal narratives of youth and the master narrative of Palestine. The interviews showed the complexity of individual self-constructions within the 
Palestinian identity as the participants in the study struggled with an identity constructed around the master narrative of the historical Palestinian and their individual narrative as a teenager. Timberlake (1994) further captured the multidimensionality of the self-concept of 200 homeless children who clung to the other domains of the self, such as that of an academic self, in order to buffer against the negative external and internal self-perceptions associated with homelessness. Although individually the above studies are limited in their application of the findings across populations and contexts, the studies combined provide evidence for theoretical implications which support the influence of the internalised experience of being a member of an oppressed group on the participants' self-concept and the various resources and coping strategies drawn upon to preserve their sense of self.

Additional descriptive self-concept domains were apparent within the studies, which included self-regard, self-efficacy, self-worth, and self-esteem. Egan and Perry (1998), for example, tested whether self-regard contributes overtime to victimisation by peers especially when selfregard was assessed in terms of self-perceived peer social competence. Additionally, they sought to measure if vulnerabilities were more likely to lead to victimization over time when children had low self-regard. The findings supported the experience of being victimized to lead to a diminished self-regard over time. Confidence in one's peer group association served as a protective factor for behaviourally at-risk children from victimisation. These results supported a conceptualization of high self-regard to be an adaptive coping resource in stressful or threatening situations. Although the sample utilised a large sample size $(n=189)$ and a range of age groups (grade 3-7), the homogeneous white middle-class sample limited the generalization of the findings to other groups. An additional limitation was that the study only explored one type of victimisation (direct, overt verbal and physical abuse by peers), while other kinds of victimization could have a different relation to the self-concept.

Discursive Practices Various forms of discursive practices were emphasized to play a central role in the meaning making processes surrounding child self-concept within many of the studies. The studies which focused on this proposed the self to be constructed through discourse. For example, language, specifically in the form of talk with others, was a means through which the participants made sense of themselves and their social world. For example, McLean and Breen (2009) examined narrative identity in adolescence in terms of narrative content and processes. The study demonstrated how simply learning about the self does not predict self-esteem in middle and late adolescence rather this occurs through constructing experiences through negative to positive discourse. The study by McLean and Jennings (2012) explored the role of peer and parental discourse, specifically focusing on the role of friends in comparison to mothers in adolescent narrative identity development. The results showed how the narrative identity development of the teenage participants occurred simultaneously with intimacy development with friends and mothers. The findings additionally supported the meaning-making process of narrative identity development to occur through the reflection of past events which became integrated into the self-concept through discourse. Limitations of the study included the demographics and size of the study which excluded the exploration of the complexity which gender, race, and SES may contribute towards adolescent narrative identity development. The longitudinal study by Reese et al. (2010) conceptualised how 
children draw meaning from important life events and how this influenced the development of a self-concept through examining parent and child conversations. The findings supported personal narratives to be linked to self-understanding throughout development. The emotional content of parent reminiscing was found to be most important for child self-concept. Future longitudinal research should seek to capture both the continuity and change in the self-concept over time. A second study by Reese and colleagues (2007) examined the relation between talk about past events with talk about on-going emotions and events for self-development amongst fifty-one five and six-year-old New Zealand children and their parents. Conversations about negative past events where parents' reference the child's negative emotions and to negative evaluations of the child and event, were related to children's self-esteem. Additionally, parental explanation of negative emotions in the conversations was positively related to the children's stable self-concept. Welch-Ross et al. (1999) similarly explored the influence of discourse on self-concept amongst young children through analysing the emotional content of mother-child conversations about past events and references made to mental states during these conversations. The extent to which children elaborated on the emotional aspects of past experience in their personal narratives was related to the organization of their psychological self-concepts. The authors recommended further research focus on the relation between the development of self-knowledge and autobiographical memory and the need for longitudinal research to determine the relation between age, self-knowledge, and the establishment of autobiographical memories. Bohanek et al. (2006) looked beyond mother-child conversations to how meaning was negotiated as families constructed narratives. Within the study, three family narrative styles emerged including the coordinated perspective, individual perspective and imposed perspective. Families who engaged in a coordinated perspective style tended to have children, especially girls, who had higher self-esteem, and families who engaged in an individual perspective style had children, especially boys, with a more external locus of control. The study provides implications for how the role of family narratives may be particularly critical for children's self-constructions. The sample of participants resulted in some limitations, including the size and demographics. The majority of the participants came from well-adjusted families, with implications for future research to examine family narratives amongst larger samples and across cultural and socioeconomic backgrounds.

Valentine (2000) explored the ways in which British children are positioned within a social and culturally prescribed identity narrative. Within these influences, age and gender played a key role in how the young people constructed a sense of self, as the narratives of the young people negotiated and challenged the ascribed gender and age identities and their meanings. For example, the identity of children in Britain has been historically defined in opposition to adults, however recently children have been increasingly positioned within the narratives of individualisation, with an increasingly independent entry into their sociocultural environment. The research provided valuable insight into the identity construction of British children whose experiences lie within a particular set of narratives. Further research in other contexts could provide complimentary evidence into child self-constructions amongst children who are located within the narratives of other histories and cultures. Hammack (2010), for example, 
explored the relationship between the identity constructions of Palestinian children and the master narrative of Palestinian history and collective identity. The findings revealed the historical narrative of the Palestinian identity to become internalised as a part of the individual identity. However, the personal narrative of the participants was at times constructed in opposition to the Palestinian master narrative, which influenced the construction of an identity in divergence to the master narrative. The authors note that the participants in the study represented a theoretical, rather than representative sample of Palestinian children.

Socio-Environmental Conditions Socio-environmental conditions were presented in the majority of the studies to have a strong influence on a child's self-concept. Conditions such as poverty and a lack of social infrastructure in the neighbourhood placed limits on the participants' access to vital resources for constructing a healthy self-concept. This is seen in the ethnographic study by Moses (2006) amongst 63 children aged 10-18 from Ocean View, South Africa. The study showed how social and economic capital was not equally accessible to all people and how this influenced the self-concept of the local children. The children in the study expressed opposition to the negative identities and assumptions imposed on them from external sources based on the community's reputation for poverty and violence. Many of the children attached their own meaning to their identity and community through their positive engagement of the public space and with their peers. Positive social relations with both peers and adults in the community enabled children to build a sense of collective self-efficacy and selfesteem. The study by Timberlake (1994) highlighted the concept of self as homeless as children engaged with their unstable living environment. The participants in the study included 200 children aged 6 to 12 years old who took part in individual interviews accompanied by a teacher survey which measured psychosocial functioning. Despite the devalued perceptions of others around homelessness, the children's responses emphasised their drive to reconstruct a mental representation of the self as valued. Other children in the study, however, may have internalised the negative image of a devalued self, which consequently resulted in poorer psychosocial functioning, specifically in the form of academic performance. The mixed methods approach to the study provided valuable insight into the coping strategies and barriers for children under-going homelessness and how these influence the self-concept. While the teacher survey provided valuable information regarding the psychosocial functioning of the participants, it would be valuable to include the survey amongst the parents and the participants themselves in order to have a more holistic understanding of the influences of homelessness on the participants' self-concept and wellbeing.

The influence of life on the street on children's self-concept is further captured in the study by Campos Monteiro and Dollinger (1998), which aimed to analyse street children's photographic depiction of their perceptions of themselves and their environment. Three themes were identified as a part of the children's reality of living or working on the street including; images of physical environment, social-collective orientation in the social environment, and aspects of individual self-identity. A strong sense of collective identity emerged as the children described their family, friends, and community connections. Despite 
social marginalisation, many of the children identified their selfhood to be connected to positive aspirations for the future. The negative aspects of life on the street were also included in the photos, such as the realities of prostitution, abuse and neglect, all of which influenced the ways in which the children constructed self-meaning. A limitation of the study included the sampling of the participants, who were all attending a local project for children who spent most of their time on the street. Future research could benefit from exploring the influences of the street life on the self-concept of children who are not attending a formalised programme. These children may have a different experience of life on the street and may lack access to the same resources as those who are attending a programme.

Oppression and Marginalisation A substantial amount of evidence supported conditions of oppression and marginalisation based on race, ethnicity and gender to have a strong influence on the self-concept of the participants. Those participants who were able to make sense of their circumstances, who had awareness of their historical situation as a marginalised group, and who were able to access adequate social support, were seen to have more positive outcomes in self-concept development. Other participants struggled to overcome the conditions of oppression, internalising negatively the perceptions from the dominant culture as a reflection of the self. Anagnostopoulos et al. (2006) investigated how a traumatic situation, such as forced migration, may affect the process of identity formation in adolescence. Using a case study approach, the study examined the experiences of two adolescent males who were forced to immigrate to Greece where they were faced with further marginalisation as a part of a minority ethnic group. The adolescents in the study negatively internalized their disruptive traumatic processes as they struggled to establish a personal identity which remained conflicted between the cultures of their community of origin and their new community. The study supports how violent changes within an adolescent's relationship to other ethnic groups may trigger the process of disturbed identity formation and lead to a negative self-internalization. Although the case-study approach provided valuable insight into the affects which a traumatic situation, such as forced migration, could have on identity development, further research amongst a larger sample of participants and across immigrant groups could provide further insight into the processes of identity formation for immigrant children and adolescents.

The influence of gender and racial oppression on the self is investigated in Johnson (2014). The study aimed to understand the implications of a loss of a friend to homicide on the psychosocial process of identity development amongst urban African American teenage girls. Amongst the participants, the loss of a friend was commonly integrated into a sense of self often in a meaningful and reflective way. The self-concept of the girls in the study was also influenced by the often conflicting messages from their experiences within the dominant culture, their culture as an African American female, and their experiences as a socially marginalized group. Shifts in self-concept were seen towards a stronger religious or spiritual identity and towards a stronger racial identity based on the awareness of social, racial and gender devaluation. A stable self-concept, sense of social awareness around injustices, claim to social service accountability, and consciousness of the larger issues of race and oppression all contributed towards the participants' resilience. 
The self-concept within the social and psychological dynamics of racial and class membership were further described by Lim (2008). The study specifically highlighted the influence of class background and ethnicities in developing an academic identity. Middle class white students could more easily adopt an identity as a good student than students from a lower class and from an African American background, regardless of their academic capabilities. Likewise, boys were able to more easily adopt an identity as good mathematics students than girls of all classes, reflecting the conflicting identity of femininity versus the authoritative masculine field of mathematics. Also based within an academic setting, De Haan et al. (2010) sought to understand the role that diversity plays in collaboration patterns and knowledge construction in multi-ethnic classrooms. Students from a minority background had a tendency to resist identities which were not seen as being in accordance with their group, reflected within the academic and the social discourse of the groups. While Dutch students were able to represent the more dominant role in the academic discourse, they lost this position in the informal nonacademic discourse. Additionally, while ethnic minority youth demonstrated a lower selfconcept when it came to academics, this was not reflected in their social sense of self.

Whitesell et al. (2006) shed light on the positive aspects of the meaning ascribed to an identity as an American Indian youth. The study participants developed a strong sense of self around a positive personal identity and a strong collective identity despite a history of social marginalisation and oppression. Although the youth in the study lived in reservations where they were faced with difficult circumstances such as poverty, unemployment, isolation, substance abuse, and violence, the majority of American Indian adolescents in this study had both high self-esteem and a strong often bicultural collective identity. An interesting point for investigation could be around the meaning ascribed to an American Indian youth identity amongst American Indian youth who do not reside within a reservation, thus may experience further disconnect from their ethnic culture.

Culture The theme of culture posed a notable influence on the participants' conceptualisation of the self. This was especially evident within the studies which included ethnic minority or previously disadvantaged participants. Rogers et al. (2012) showed how meaning around ethnic identity emerged throughout middle childhood within a sample of Chinese, Dominican, Russian, White, and Black American children in New York city who were second-generation immigrants. While a variation of meaning emerged amongst ethnic groups, children described their ethnic identity to be formed around language, physical appearance, social position, culture, and pride. It would be valuable for further research to explore the meaning around ethnic identity amongst first generation immigrants, across different age groups, and overtime. While Rogers et al. (2012) focused on the emergence of ethnic identity throughout middle childhood, Wang (2004) examined the emergence of cultural self-constructs from two different societies amongst early childhood participants through the use of the open-ended free narrative method. The data revealed critical differences in the structure and content of autobiographical memories and self-descriptions in European American and Chinese children as young as age 3 and 4. Chinese children placed a greater emphasis on social interactions and on the roles of other people than the American children, 
who showed a tendency to focus on their own roles, feelings, and opinions. The research suggests that the autobiographical memory and self-concept are two interrelated constructs of meaning that emerge in the context of culture. Different cultural values and self-beliefs are seen within the everyday activities, playing a crucial role in shaping a child's selfdevelopment.

Also amongst early childhood participants, Gernhardt et al. (2014) examined the conceptions of self and family held by migrant Turkish preschool children, as expressed in their drawings of themselves and their families. The drawings of children from five cultural milieus provided insight into the perceptions of the self and family. Examples of significant cultural differences were seen in gender specific features, emotional relatedness, and size.

In addition to individual identity, collective identity was commonly a part of the cultural self-constructions of children and youth. Fernández-Kelly and Schauffler (1994) highlighted the role of collective identity as a significant resource in the process of assimilation for immigrant children. In the study, collective self-definitions were formed through the process of segmented assimilation as immigrants interacted with other ethnic groups. This presented the ways in which immigrant children construct a sense of self based on the perceptions of others in their environment and in comparison to other more marginalised immigrant individuals or groups. Whitesell et al. (2006) additionally described the cultural self-concepts of American Indian reservation youth to be comprised of both a positive personal identity and a strong collective identity, both of which provide avenues to a healthy self-development. Valentine (2000) further explored the idea of collective self-identity through an examination of the social processes involved in the everyday construction of individual and collective selves among eleven to sixteen-year-olds in a middle income school in the UK. The study highlighted the complex and fragmented nature of adolescent self-conceptions as the participants negotiated their individuality against their peer group identities and against the adult-imposed identity of childhood.

Social Support The final thematic category which emerged from the studies is that of social support. Across the studies, social networks revealed to be a key influence on both a positive and negative self-concept for the study participants. Forms of social support included family, peers, adults in the community, mentors, coaches, and social service providers. This is evident in a study by Noble-Carr et al. (2013), who explored the critical role of identity and meaning in the lives of vulnerable adolescents who were enrolled in youth support services and the implications of this for supporting their needs. The findings emphasized the need to assist young people to understand the psychosocial benefits of positive social connections. Additionally, the study implied that there is a need for support services to emphasise and understand issues around young peoples' personal identity and meaning-making. Moss (2009) further explored the role in which social support contributes to identity development of youth in residential and non-residential care. Interviews were conducted amongst twenty, 4 to 18-year-old indigenous Australian young people focused on self-identity. The participants demonstrated key differences in terms of connectedness, self-esteem, identity, and psychological well-being amongst the children in residential care compared to those who 
were not. Young people not in care across all age ranges and genders were much more connected to their family of origin and extended family and identified culture and cultural practices as being important to their sense of self. Young people in care were much more likely to have lost contact with father, mother, siblings and extended family and thus were more likely to have challenges with attachment, trust, emotional regulation, and self-esteem. They additionally displayed a lack of cultural knowledge and a poorer sense of self. Also focusing on youth in residential care, McMurray et al. (2011) presented an analysis of semistructured interviews with 13 young people in residential and non-residential care and their social workers. The young people in the sample presented different identities in different contexts which were largely shaped by their relationships. The findings showed how positive social relationships can support a healthy self-development despite adverse environmental circumstances. The study revealed the differences between the social workers' perspectives of the influences on the identity of children versus the perspectives of the children themselves, further illuminating the need to include children in the research process.

Abrams and Aguilar (2005) explored the role which social support played on the self-concept of juvenile offenders. The study aimed to explore how young male teenagers deal with expectations to change their ways of conceptualizing their past, present, and future selves in the context of a six-month residential program that included both cognitive-behavioural therapy and behaviour modification approaches. The images of the self were constructed in relation to close friends and family members. Images of role models which the participants could identify with and an ability to take personal responsibility helped the offenders to create images of hoped for selves. While offenders showed improvements in strategies for selfgrowth while in treatment, they struggled to view these strategies as attainable within their regular social environments, emphasising the challenge of crime temptations upon release. While skills development and planning on how to deal with criminal influences and how to improve social support for the adolescents' may influence positive behavioural change, this may be limited when applied to youth offenders' real-world situations where the larger community and structural challenges must also be taken into account. Because the data was collected at only one facility with a specific treatment model, it would be interesting to explore how youth conceptualise the self within other treatment models or in other facilities.

Within the theme of social support, attachment to caregivers was additionally identified as having an impact on the child's self-development. An example of this is seen in the study by Macfie and Swan (2009) which assessed representations of the caregiver-child relationship and of the self, and emotion regulation among a sample of 30 children aged 4 to 7 whose mothers had Bipolar Disorder (BPD) in comparison to 30 normative cases. The results of the study showed that children whose mothers have BPD told stories in which the child's self was represented as more incongruent and shameful than the normative group. Additionally, the child's maladaptive self-concept was significantly correlated with maternal self-harm.

The social support within the therapeutic relationship was also shown to influence a child's self-concept. The narrative case study by Cockle (1994) demonstrated the importance of one to one time with an unconditionally accepting adult in facilitating self-growth through 
the use of the art self-portrait process with a six-year-old boy. Through the therapeutic process, the child expressed feelings of insecurity of self and environment which gradually decreased overtime and emerged as feelings of self-acceptance, self-love, and self-growth. The implications of the study focus on how the process of drawing combined with an accepting relationship could lead to self-growth and feelings of security and freedom.

\section{Discussion}

Current research related to children's meaning assignations and constructions of the self supports the ways in which children construct a self-concept to be strongly tied to the ways in which children make sense of their well-being. The studies reveal the importance of locating the self within an individual's proximal matrix of social, cultural, structural and environmental influences. Timberlake (1994) for example demonstrated how children living in poverty, who are able to make sense of self and social situation of homelessness, have higher levels of subjective well-being. Anagnostopoulos et al. (2006) further discussed how the negative self-internalisation of the views of others on a minority's ethnic group can lead to a disruption in psychosocial well-being, specifically in the form of shame and self-hatred. Moses (2006) demonstrated how children who live within an impoverished community assign meaning to the self in coordination with their understanding of their marginalised economic and social position in society which limits their access to resources for their well-being.

Within the reviewed studies, the notion of self-concept was identified to be a fluid, situational and multi-dimensional phenomenon. The young people in the studies often created different identities in different contexts and could show an inflated self-concept in one domain simultaneously with a negative self-concept in another. Culture and age were highlighted to influence both conflictual and changing notions of the self. The majority of the studies took place amongst an adolescent population which could be related to the level of cognitive and social development of the participants that allow for meaning-making. However, studies such as Welch-Ross et al. (1999) support children as young as 3 years to be in the continuous process of constructing meaning around the self. A large portion of the studies support the process of self-conceptualization to be driven through narratives, emphasising the ways in which children continuously create and reconfigure their self-concept within their discourses. While narratives were the main tools adolescents utilised for their self-development, preschool-age children were shown to use avenues such as art and play to assist them in their selfconstructions (See Ahn and Filipenko 2007; Gernhardt et al. 2014; Moss 2009; Welch-Ross et al. 1999).

The majority of the studies utilised a qualitative approach, which cannot be generalized across populations. However, the studies were conducted across various countries, cultures, ages and genders, all of which create a more cohesive understanding of the processes through which children and adolescents construct a self. The studies additionally highlight the impact which one's socio-political and historical situation have on the self. Conditions of oppression have shown to have a negative impact on an individual's healthy selfdevelopment. This is seen in studies amongst South Africans, African Americans, Dominican Americans, Chinese Americans, Native Americans, Palestinian children, 
migrant youth in Greece, minority youth in Holland, and aboriginal youth in Australia. Prejudice and racism within these studies placed the participants in situations where they had to negotiate their self-concept against social mainstream messages of racial or cultural inferiority. While some youth responded through a strong prideful racial or cultural identity, others appeared to struggle with feelings of shame and self-hatred. Academic self-concept was additionally affected by racial, ethnic, and gender stereotypes (See De Haan et al. 2010; Lim 2008; Roth 2006). Females in the studies, for example, struggled with unrealistic self-body images and negative messages around their academic and athletic capabilities (See Johnson 2014; Lim 2008). This implies that in order to truly understand children's self-constructions, one must take into account the larger historical and structural conditions within the child's specific context.

Resilience was a common influence on the healthy self-development of the young people within the studies. While many young people were faced with negative interactions within their environment, they seemed to resort to various means of coping in order to preserve their sense of self. An example is seen in Timberlake (1994), where the participants placed a great amount of energy into constructing a mental representation of 'self' as valued and competent in order to combat the negative self-messages associated with homelessness. For some participants, resilience meant discounting the self-domains which they did not excel in, such as an academic self, while clinging to the more positive domains.

An individual's sense of hope and future is additionally revealed to be a means of nurturing a healthy sense of self in the face of adversity. Abrams and Aguilar (2005) and Clinkinbeard and Murray (2012) highlighted the importance of the 'possible selves theory,' where young people are met with the conflict of their possible future selves versus their feared selves. Those who could produce a clear picture of their future self, and a have a realistic plan for achieving this, showed greater psychosocial outcomes. These outcomes came coupled with adequate social support and community resources. Children from marginalised groups in Australia, USA, Pakistan, Greece, and the UK struggled with the similar processes of identity development as they attempted to construct a sense of self within contexts of racial, cultural, and historical oppression. Consciousness raising had an impact on the healthy self-development of many of the marginalized youth. The young people who seemed to have a good understanding of their racial or cultural history were able to construct a healthier sense of self, despite negative social messages related to their race or ethnicity (See Graham and Anderson 2008; Johnson 2014; Roth 2006; Whitesell et al. 2006). This emphasises the importance which issues of social justice and equity play on an individual's self-concept.

\section{Conclusions and Recommendations}

The current systematic review elucidates the various means children utilise to construct and assign meaning to the self. Current research has explored this across a variety of socioeconomic, historical, and ethnic contexts. A notable amount of the literature, however, takes place within the United States and a disproportionate amount amongst a middle-class adolescent population. The current systematic review provides evidence to the ways in which children construct a self from various age groups and supports children from early childhood 
through adolescence to be capable of the self-meaning making processes. Due to the broad age group, the current review lacks an in-depth analysis of how specific age groups vary in their self-constructions and how self-constructions and meaning making processes may change or evolve throughout one's life span. There additionally remains a need for further research in more diverse contexts, especially in developing countries and amongst early and middle childhood children from lower and higher socioeconomic environments. The study also highlights the multidimensional and situational nature of the self. Even within a United States context, the ways in which young people constructed a sense of self varied and were largely dependent on their social, historical, and cultural position within the country's immense social matrix.

The study additionally emphasises that the self-concept is mutually influenced and supported by an individual's immediate social networks and environmental resources. Children who live in conditions of poverty, especially those faced with high levels of community and domestic violence, are particularly affected as resources available for a healthy self-development are limited. Poverty and oppression, however, do not necessarily result in a negative selfconcept. Several studies amongst children within impoverished communities revealed that many of the participants construct a healthy sense of self, despite oppressive conditions. This was often influenced by their immediate social interactions. Due to the lack of research available specifically related to children in poverty as well as the unique experience within a specific community, further research is necessary for understanding how conditions of poverty influences the self-concept of children across contexts and cultures.

The implications of this study point to the importance of considering the self-concept as being crucial for child well-being. These activities must look to the contextual meaningmaking processes which surround the self-identity of young people. The interventions should also be inclusive of positive social support networks. These networks are especially beneficial if available on the structural, community, and individual levels and range from social service providers, teachers, community mentors, family members, and peers. Additionally, interventions should be inclusive of the individual and contextual issues influencing child selfconcept including coping skills, structural challenges and proximal economic and social resources.

Current intervention programmes commonly utilise models based on the assumptions of the objective measures of child well-being developed in Western countries. However, how children feel about themselves remains marginalised on the child well-being agenda. Evidence from this review supports issues of self-concept as playing a pivotal role in how children make sense of their well-being. The complex nature of the self implies that there is not a single self-concept intervention which could fit all children. Rather, the intervention must be developed around the views of the children themselves within the specific context where the intervention is intended. This provides a powerful rationale for research related to child wellbeing to create more space for the voices of children, especially those from more marginalised communities and countries, regarding issues around their well-being. Such research should focus on the subjective nature in which children construct and assign meaning to the self. 


\section{References}

Abrams, L. S., \& Aguilar, J. P. (2005). Negative trends, possible selves, and behavior change a qualitative study of juvenile offenders in residential treatment. Qualitative Social Work, 4(2), 175-196.

Adams, G., \& Markus, H. R. (2004). Toward a conception of culture suitable for a social psychology of culture. The psychological foundations of culture (pp. 335-360). Mahwah: Lawrence Erlbaum Associates Publishers.

Ahn, J., \& Filipenko, M. (2007). Narrative, imaginary play, art, and self: intersecting worlds. Early Childhood Education Journal, 34(4), 279-289. doi:10.1007/s10643-006-0137-4.

Anagnostopoulos, D. C., Vlassopoulos, M., \& Lazaratou, H. (2006). Forced migration, adolescence, and identity formation. The American Journal of Psychoanalysis, 66(3), $225^{-237 .}$

Bennion, A. E., Shaw, R. L., \& Gibson, J. M. (2012). What do we know about the experience of age related macular degeneration? A systematic review and meta-synthesis of qualitative research. Social Science \& Medicine, 75(6), 976-985.

Blascovich, J., \& Tomaka, J., (1991). Measures of self-esteem. Measures of Personality and Social Psychological Attitudes, 1, 115-160.

Bohanek, J. G., Marin, K. A., Fivush, R., \& Duke, M. P. (2006). Family narrative interaction and children's sense of self. Family Process, 45, 39-54.

Bohanek, J. G., Marin, K. A., \& Fivush, R. (2008). Family narratives, self, and gender in early adolescence. The Journal of Early Adolescence, 28, 153-176. doi:10.1177/02724316073086732.

Bracken, B. A., Lamprecht, M. S. (2003). Positive self-concept: an equal opportunity construct. School Psychology Quarterly, 18(2), 103.

Campos Monteiro, J. M., \& Dollinger, S. J. (1998). An autophotographic study of poverty, collective orientation, and identity among street children. The Journal of Social Psychology, 138(3), 403-406. Clinkinbeard, S. S., \& Murray, C. I. (2012). Perceived support, belonging, and possible selves strategies among incarcerated juvenile offenders1. Journal of Applied Social Psychology, 42(5), 1218-1240.

Cluver, L., \& Gardner, F. (2007). Risk and protective factors for psychological well-being of children orphaned by AIDS in Cape Town: a qualitative study of children and caregivers' perspectives. AIDS Care, 19(3), 318-325.

Cockle, S. (1994). Healing through art: the self-portrait technique. International Journal of Play Therapy, 3(1), 37-55. doi:10.1037/hoo89188.

Cooley, C. H. (1902). Human nature and the social order. New York: Scribner.

De Haan, M., Keizer, R., \& Elbers, E. (2010). Ethnicity and student identity in schools: an analysis of official and unofficial talk in multi-ethnic classrooms. European Journal of Psychology of Education, 25(2), 176- 191.

Demaray, M. K., Malecki, C. K., Rueger, S. Y., Brown, S. E., \& Summers, K. H. (2009). The role of youth's ratings of the importance of socially supportive behaviors in the relationship between social support and self-concept. Journal of Youth and Adolescence, 38(1), 13-28.

Dixon-Woods, M., Agarwal, S., Jones, D., Young, B. \& Sutton, A. (2005). Synthesising qualitative and quantitative evidence: a review of possible methods. Journal of Happiness Services Resarch \& Policy, 10(1), 45-53B. 
Dolman, C., Jones, I., \& Howard, L. M. (2013). Pre-conception to parenting: a systematic review and meta-synthesis of the qualitative literature on motherhood for women with severe mental illness. Archives of Women's Mental Health, 16(3), 173-196.

Donnelly, N. A., Hickey, A., Burns, A., Murphy, P., \& Doyle, F. (2015). Systematic review and meta-analysis of the impact of carer stress on subsequent institutionalisation of community-dwelling older people. PloS One, 10(6), e0128213.

Egan, S. K., \& Perry, D. G. (1998). Does low self-regard invite victimization? Developmental Psychology, 34(2), 299-309. doi:10.1037/0012-1649.34.2.299.

Fattore, T., Mason, J., \& Watson, E. (2007). Children's conceptualisation (s) of their wellbeing. Social Indicators Research, 80(1), 5-29.

Fernández-Kelly, P. M., \& Schauffler, R. (1994). Divided fates: immigrant children in a restructured U.S. economy. International Migration Review, 28(4), 662-689.

Garg, A., Hackman, D., \& Tonelli, M. (2008). Systematic review and meta-analysis: when one study is just not enough. Clinical Journal of the American Society of Nephrology, 3, 253-260. doi:10.2215/CJN. 01430307.

Gernhardt, A., Rübeling, H., \& Keller, H. (2014). Self-and family-conceptions of Turkish migrant, native German, and native Turkish children: a comparison of children's drawings. International Journal of Intercultural Relations, 40, 154-166.

Graham, A., \& Anderson, K. A. (2008). BI have to be three steps ahead": academically gifted African American male students in an urban high school on the tension between an ethnic and academic identity. The Urban Review, 40(5), 472-499.

Guerra, N. G., Rowell Huesmann, L., \& Spindler, A. (2003). Community violence exposure, social cognition, and aggression among urban elementary school children. Child Development, 74(5), 1561-1576.

Hammack, P. L. (2010). The cultural psychology of Palestinian youth: a narrative approach. Culture \& Psychology, 16(4), 507-537.

Harter, S. (1982). The perceived competence scale for children. Child Development, 53, 87-97.

Hung, D., Lim, S. H., \& Jamaludin, A. B. (2011). Social constructivism, projective identity, and learning: case study of nathan. Asia Pacific Education Review, 12(2), 161-171.

Isom, D. (2007). Performance, resistance, caring: racialized gender identity in African American boys". Urban Review, 39(4), 405-423. doi:10.1007/s11256-007-0061-y.

Johnson, C. M. (2014). The loss of friends to homicide and the implications for the identity development of urban African American teen girls. Clinical Social Work Journal, 42(1), 27-40.

Kenny, M. C., \& McEachern, A. (2009). Children's self-concept: a multicultural comparison. Professional School Counseling, 12(3), 207-212.

Kiang, L., \& Fuligni, A. J. (2010). Meaning in life as a mediator of ethnic identity and adjustment among adolescents from Latin, Asian, and European American backgrounds. Journal of Youth and Adolescence, 39(11), 1253-1264.

Kickett-Tucker, C. (2009). Moorn (Black)? Djardak (White)? how come I don't fit in mum?: exploring the racial identity of Australian Aboriginal children and youth. Health Sociology Review, 18(1), 119-136.

Lim, J. H. (2008). Adolescent girls' construction of moral discourses and appropriation of primary identity in a mathematics classroom. ZDM, 40(4), 617-631. 
Long, A. F., \& Godfrey, M. (2004). An evaluation tool to assess the quality of qualitative research studies. International Journal of Social Research Methodology, 7(2), 181-196.

Macfie, J., \& Swan, S. A. (2009). Representations of the caregiver-child relationship and of the self, and emotion regulation in the narratives of young children whose mothers have borderline personality disorder. Development and Psychopathology, 21(03), 9931011.

Margolin, G., \& Gordis, E. B. (2000). The effects of family and community violence on children. Annual Review of Psychology, 51(1), 445-479.

McLean, K. C., \& Breen, A. V. (2009). Processes and content of narrative identity development in adoles-cence: gender and well-being. Developmental Psychology, 45, 702-710.

McLean, K. C., \& Jennings, L. E. (2012). Teens telling tales: how maternal and peer audiences support narrative identity development. Journal of Adolescence, 35(6), 14551469.

McLean, K. C., Breen, A. V., \& Fournier, M. A. (2010). constructing the self in early, middle, and late adolescent boys: narrative identity, individuation, and well-being. Journal of Research on Adolescence (Wiley-Blackwell), 20(1), 166-187. doi:10.1111/j.15327795.2009.00633.x.

McMurray, I., Connolly, H., Preston-Shoot, M., \& Wigley, V. (2011). Shards of the old looking glass: restoring the significance of identity in promoting positive outcomes for looked-after children. Child \& Family Social Work, 16(2), 210-218.

Mead. (1934). George Herbert Mead. BThe self and the organism”. In C. W. Morris (Ed.), Section 18 in mind self and society from the standpoint of a social behaviorist (pp. 135-144). Chicago: University of Chicago.

Mellon, L., Doyle, F., Rohde, D., Williams, D., \& Hickey, A. (2015). Stroke warning campaigns: delivering better patient outcomes? A systematic review. Patient Related Outcome Measures, 6, 61.

Moses, S. (2006). The impact of neighbourhood-level factors on children's everyday lives, well-being and identity: a qualitative study of children living in Ocean View, Cape Town. Social Dynamics, 32(1), 102- 134. doi:10.1080/025339506086287214.

Moss, M. (2009). Broken circles to a different identity: an exploration of identity for children in out-of-home care in Queensland, Australia. Child \& Family Social Work, 14(3), 311-321.

Neff, K. D., Kirkpatrick, K. L., \& Rude, S. S. (2007). Self-compassion and adaptive psychological functioning. Journal of Research in Personality, 41(1), 139-154.

Noble-Carr, D., Barker, J., \& McArthur, M. (2013). Me, myself and i: identity and meaning in the lives of vulnerable young people. Institute of Child Protection Studies, Australian Catholic University (1994).

Pearson, A. (2004). Balancing the evidence: incorporating the synthesis of qualitative data into systematic reviews. JBI Reports, 2(2), 45-64.

Piers, E. V. (1969). The perceived competence scale for children. Child development 53. Manual for the Piers-Harris children's self concept scale (pp. 87-97). Nashville: Counselor Recordings and Tests.

Purdie, N., Tripcony, P., Boulton-Lewis, G., Gunstone, A., \& Fanshawe, J. (2000). Positive selfidentity for indigenous students and its relationship to school outcomes. Canberra: Commonwealth Department of Education, Training and Youth Affairs. 
Reese, E., Bird, A., \& Tripp, G. (2007). Children's self-esteem and moral self: links to parent- child conversations regarding emotion. Social Development, 16, 460-478. doi:10.1111/j.1467-9507.2007. 00393.x.

Reese, E., Yan, C., Jack, F., \& Hayne, H. (2010). Emerging identities: Narrative and self from early childhood to early adolescence. Narrative development in adolescence (pp. 2343). US: Springer.

Rogers, L. O., Zosuls, K. M., Halim, M. L., Ruble, D., Hughes, D., \& Fuligni, A. (2012). Meaning making in middle childhood: an exploration of the meaning of ethnic identity. Cultural Diversity and Ethnic Minority Psychology, 18(2), 99.

Rosenberg, M. (1965). Society and the adolescent self-image. Princeton: Princeton University Press.

Roth, W. M. (2006). Identity as dialectic: Making and Re/making self in urban schooling. In J. L. Kincheloe, K. Hayes, K. Rose, \& P. M. Anderson (Eds.), The Praeger handbook of urban education (pp. 143-153). Westport: Greenwood.

Savahl, S., Malcolm, C., Slembrouk, S., Adams, S., Willenberg, I. A., \& September, R. et al. (2015). Discourses on well-being. Child Indicators Research, 1-20.

Schwartz, D., \& Gorman, A. H. (2003). Community violence exposure and children's academic functioning. Journal of Educational Psychology, 95(1), 163-173. doi:10.1037/00220663.95.1.163.

September, R., \& Savahl, S. (2009). Children's perspectives on child well-being. The Social Work Practioner-Researcher, 21(1), 23-40.

Staub, E. (2003). Notes on cultures of violence, cultures of caring and peace, and the fulfillment of basic human needs. Political Psychology, 24(1), 1-21.

Timberlake, E. M. (1994). Children with no place to call home: survival in the cars and on the streets. Child \& Adolescent Social Work Journal, 11(4), 259-278.

Valentine, G. (2000). Exploring children and young people's narratives of identity. Geoforum, 31(2), 257-267.

Wang, Q. (2004). The emergence of cultural self-constructs: autobiographical memory and selfdescription in European American and Chinese Children. Developmental Psychology, 4O(1), 3-15. doi:10.1037/0012-1649.40.1.3.

Welch-Ross, M. K., Fasig, L. G., \& Farrar, M. J. (1999). Predictors of preschoolers' selfknowledge: reference to emotion and mental states in mother-child conversation about past events. Cognitive Development, 14(3), 401-422.

Wells, M., Williams, B., Firnigl, D., Lang, H., Coyle, J., Kroll, T., \& MacGillivray, S. (2013). Supporting 'work-related goals' rather than 'return to work'after cancer? A systematic review and meta-synthesis of 25 qualitative studies. Psycho-Oncology, 22(6), 12081219.

Whitesell, N. R., Mitchell, C. M., Kaufman, C. E., \& Spicer, P. (2006). Developmental trajectories of personal and collective self-concept among American Indian Adolescents. Child Development, 77(5), 1487-1503. 